\title{
Supporting sustainable e-learning
}

\author{
Allison Littlejohn \\ Centre for Academic Practice, University of Strathclyde \\ email: allison.littlejohn@strath.ac.uk
}

This paper draws upon work carried out within phase one of a national forum for support staff, funded by the UK Learning and Teaching Support Network Generic Centre. It sets out themes in current Learning Technology research within the context of institutional practice. It reports the responses of a range of e-learning support staff to new developments in the reuse and sharing of Learning Objects. The article highlights tensions across support units, inconsistencies in support provision and confusion over issues concerning different modes of teaching. It also forewarns a growing gap between institutional practice and research in the development of approaches to sustainable $e$ learning.

\section{Issues in developing flexible and sustainable e-learning}

The United Kingdom government recently published a consultation document 'Towards a Unified E-Learning Strategy' focusing on flexible and sustainable e-learning (Department for Education and Skills (DfES), 2003a). This document envisions e-learning as an integral aspect of the learning and teaching environment, in which networked learners access richly structured, highly accessible, interactive settings (MacFarlane, 1998; National Committee of Inquiry into Higher Education (NCIHE), 1997; DfES, 2003b). This vision of flexible access to learning is shared by governments across the world who appreciate e-learning as being one way of providing education that can be adaptable and cost effective.

Huge investments have already been made to provide an infrastructure that can support the development of flexible curricula. However, the government is seeking to drive down development costs mainly through the promotion of sustainable approaches to e-learning (NCIHE, 1997, Appendix 2). Central to this approach is attaining a balance between costs and strategic benefits (Nicol and Coen, 2003). Evaluation of the benefits of e-learning is largely subjective and there is an elaborate interplay between costs and benefits. An additional complication is the fact that there are a variety of social, technological and 
organizational factors that impact on the quality of teaching and learning, therefore the benefits arising from e-learning cannot be measured in isolation (Draper, Brown, Henderson and McAteer, 1996). Cost reduction is largely achieved through economies of scale, so many recent initiatives have focused upon reducing costs through the reuse and sharing of learning materials - frequently referred to as Learning Objects (for example, the JISC-funded Exchange for Learning Programme, X4L). According to Oliver and MacLaughlin (2003), 'The more reuse is considered in design, the more sustainable online teaching and learning can become.'

In an ideal world, these Learning Objects would be developed and shared by teachers and learners. They would be designed so that they could be adapted to fit different subject disciplines, levels of study and educational models (Koper, 2001). This would potentially lead to educational benefits, with students profiting from enhanced quality of learning as well as improved access (DIES, 2003c). Additional benefits that can arise from e-learning include increased innovation, enhanced public profile, increased staff satisfaction and motivation and increased wealth creation (Nicol and Coen, 2003).

Despite these claims, many lecturers remain sceptical of the perceived benefits and have been slow to adopt e-learning (Green, 1999; Campbell, 2003). Staff training in 'how to use' various types of supporting educational tools has not led to a dramatic increase in the use of these tools, for purposes other than the delivery of course materials. As Crook (2002) observed: 'Clearly academics do master other information technology tools routinely where they are perceived as powerful resources for their work.' Why, therefore, has there been limited use of e-learning tools by academics? One reason is because designing and implementing a course is much more complex than simply sending e-mail, or using Powerpoint for presentations. Academics need clear support in how to perform difficult tasks such as designing, assembling and implementing courses supported by technology. This requires a coherent, supporting infrastructure comprising not only the required technologies and network systems, but also organizational structures (for example, local and national support mechanisms), and the people that make these systems work (including support staff and learning technologists) (DfES, 2003a, para 49).

Faced with the challenge of facilitating change across institutions, support staff are frequently confronted by tensions and conflicts that arise across academic departments as well as within support units themselves (McNaught, 2002). This article outlines these tensions and describes ways in which they may inhibit the advancement of sustainable elearning. It describes the outcomes of phase 1 of a national forum for support staff, funded by the UK Learning and Teaching Support Network Generic Centre. The forum aimed to give support staff an opportunity to explore ways in which learning technology research, particularly in the area of interoperability, might impact upon future provision for elearning support. The unique aspect of this article is that it sets out current themes in learning technology research within the context of institutional practice, providing an insider view of the positive and negative aspects of existing support for e-learning. The article explores potential meanings of 'sustainable e-learning', examines current modes of support and investigates the implications of balancing costs and benefits. 


\section{Implementing a UK National Forum}

A variety of government-funded organizations already exist to support the development of sustainable e-learning. For example the Learning and Teaching Support Network (LTSN) is a national network for staff working in Higher Education, with twenty-four Subject Centres and a Generic Centre. Each centre has provided considerable support for the development of e-learning in higher education, and in doing so has begun to question the sustainable characteristics of recent developments, in particular the drive toward content creation. The LTSN has sought to promote the sustainability of e-learning by encouraging its embedding within teaching practice and through working with support staff to tease out practical strategies towards this end (Wiles and Littlejohn, 2003).

In 2003, the LTSN Generic Centre established the Supporting Sustainable eLearning Forum as an opportunity for the exchange of ideas by a wide range of support staff, educational developers and learning technologists from the United Kingdom higher and further education communities. The aim of the forum was to devise practical strategies for supporting staff in the design, development and implementation of online courses; to disseminate good practice in supporting sustainable approaches to e-learning; and to contribute to the ongoing debate on the sharing and reuse of e-learning resources. Through the forum, practitioners were invited to examine how to move e-learning on from project to embedded practice, and address questions around the scaleable nature of e-learning.

The forum had four main themes, each of which was explored during four one-day sessions held in 2003 at the University of Strathclyde (March), the LTSN Generic Centre in York (April), the Open University (May) and the University of Bristol (June). These themes were: designing sustainable online courses, implementing sustainable online courses, the design and development of reusable materials, and institutional change. Each session was based on contributions, collaboration, construction and communication of new ideas: an approach used successfully by Harris and Higgison (2003). During each session key contributors were invited to present ideas, through draft commentaries and presentations. Participants could share ideas and collaborate by brainstorming ideas during discussion fora. The ideas generated were drawn together to work towards and construct new models of staff development. These were communicated through the forum Website and an electronic discussion list.

The seventy-five forum members represented fifty different (mainly higher education) institutions from across the United Kingdom. Members were mostly support staff, including learning technologists, librarians, audio-visual staff, IT support staff and directors of learning and teaching centres. Their experiences of potential tensions in embedding sustainable e-learning and their responses to issues in current research and how this could impact upon learning and teaching practice are outlined in the following sections.

\section{What is 'sustainable e-learning'?}

E-learning is a term that is used in radically different ways by different people. Key contributor Martin Oliver led an interactive session in which he asked forum delegates to write down their personal definition of 'e-learning'. Most delegates did not find this task straightforward and a wide variety of definitions were drawn up. This is unsurprising, since 
there is similar ambiguity in the literature. Kaplan-Leiserson (2000) has a broad definition in which she asserts that e-learning is a "term covering a wide set of applications and processes, such as Web-based learning, computer-based learning, virtual classrooms and digital collaboration. It includes the delivery of content via Internet, intranet/extranet (LAN/WAN), audio and video tape, satellite broadcast, interactive TV, CD-ROM and more.' This definition alludes to the use of learning activities supported by technology; it may also refer to systems used for content delivery, for example, to distribute lecture notes, handouts and course information. Jackson (2002) attempts to differentiate between these by defining e-learning in two ways: as technology-enhanced learning and technologydelivered learning,

Technology-enhanced learning is illustrated by the numerous modes of e-learning that exploit the communicative aspects of networked technology. Many cases in point are from the field of open and distance learning, particularly within continuing professional development courses leading to professional accreditation (Timms, Booth, Crompton, Klein, Bangali and Schnuekel, 1999; Ingraham, Watson, McDowell, Brockett and Fitzpatrick, 2001). This is partly influenced by the fact that students on distance learning courses often have limited scope for dialogue with tutors and peers.

Examples of technology-delivered learning are frequently found across campus-based institutions, where students' needs and expectations are different. A study by Crook and Barrowcliff (2001) presents a representative snapshot of the use of e-learning by campusbased undergraduate students. It is interesting to note that both lecturers and students advocate the use of e-learning systems primarily to supplement the face-to-face interactions of lectures and tutorials for the distribution of lecture notes, handouts and course information. Therefore, it is important to recognize that the term 'e-learning' can describe a range of learning methodologies and also to draw distinctions across the application of e-learning for undergraduate, postgraduate, campus-based learning, distance learning and work-based education. Frequently, in discussion on e-learning, these approaches to learning are grouped together, which is confusing for academics.

Delegates were also unclear on the notion of 'sustainable'. According to the National Committee of Inquiry into Higher Education (1997, Appendix 2), sustainable e-learning is the adoption of technology to maintain teaching quality at reduced unit costs. A variety of initiatives are achieving this through economies of scale (Collis and Moonen, 2001). These programmes are focusing on the development of learning materials as Learning Objects that are described by metadata, classified and stored in digital repositories, where they can be easily accessed, recombined and reused within online courses (for example Exchange for Learning, X4L; Resource Discovery Network, RDN). For the purposes of the forum 'sustainable elearning' was defined as 'the design and development of online courses that could easily be updated or scaled up'. Central to this definition were notions of repurposing and reusing Learning Objects. This definition was not intended to be comprehensive, but rather served to help delegates and contributors discuss issues from a common perspective.

\section{How is e-learning development currently supported?}

Common perspectives in terms of e-learning support are seldom achieved. This is partly because e-learning support structures vary widely across institutions (Beetham, 2001). 
They range from centralized 'learning service', 'teaching and learning' and 'academic practice' units to decentralized support within faculties frequently located in IT support units and libraries. The staff working within these units have a variety of responsibilities (Oliver, 2003). Staff with similar roles took part within the forum, representing their respective cultures, driving forces and agendas. Therefore, it was unsurprising that forum delegates frequently had different views of e-learning and its focus. Some delegates reported that the support and advice offered to an academic seeking assistance is frequently biased towards the perspective of an individual support staff member or unit. For example, advice given to an academic seeking help from an audio-visual unit may be very different from the advice that might be given to the same academic with a similar problem by a learning and teaching unit. While it is useful to be offered a range of opinions, much of the advice offered to academics tends to focus on content, rather than on underpinning educational issues. Content issues are relatively easy to address, compared with complex pedagogical problems, and therefore may appear to offer a simple (and therefore attractive) solution.

Inconsistencies in approaches to staff support have arisen, due partly to the large number of support units existing within institutions. Inevitably, tensions arise across and between these units, leading to contradictions in support provision. This is largely caused by the uncertainty of support staff roles and identities in a rapidly changing environment (Oliver, 2002). An elearning strategy could tackle issues of poor communication between groups of support staff and with academics by aiming to promote better cohesion and collaboration. Existing strategies that have proved to be successful are frequently based upon partnerships with academic 'champions', or round-table discussion methodology (Ehrmann, 1998).

Feedback from participants indicated a variety of conflicts that hinder e-learning implementation. In an interactive session led by key contributor Gráinne Conole, forum delegates were invited to reflect upon the variety of ways in which e-learning is currently supported within their institutions and explore these underlying tensions (SSeLF, Conole briefing paper, 2003). Most institutions offer a wide range of staff development activities. These include awareness-raising events (workshops, institutional conferences, etc.) as well as tailored support, including departmental sessions, away days, one-to-one staff mentoring and institutional development projects. Many institutions provide accredited, postgraduate courses leading to membership of the UK Institute for Learning and Teaching in Higher Education. However, there is a noticeable move away from traditional workshops and courses towards developing partnership with academics (for example, on programme development, joint writing funding bids or working within formal accreditation programmes and learning and teaching committees). Another form of partnership is through joint development of learning resources (for example, online guidelines, templates and case studies or portals linking to relevant external materials and support).

Institutions have diverse implementation strategies for staff support programmes. The structure of each programme is largely influenced by a range of context-specific driving forces that vary across institutions, schools and faculties. Local drivers include research agendas, pressure from external professional organizations and partnerships with other institutions. There are additional drivers resulting from national government policy such as inclusion and quality enhancement. These influencing factors frequently contradict one 
another; however, staff support programmes have evolved that use these conflicts to their advantage. For example, programmes exploring the development of accessible learning resources can also be designed to take account of new content requirements stipulated by professional bodies.

Tensions arising between local and national agendas can result in national e-learning initiatives having limited impact at an institutional level, especially for short-term projects (Littlejohn and Peacock, 2003). Funding bodies expect that project outcomes will be easily embedded within institutions, but there has been limited institutional support for staff developers in achieving this goal. This could reflect conflicting approaches to collaboration: externally funded projects are frequently based upon the premise that collaboration among institutions is mutually beneficial. However, institutions may have a more introspective and competitive culture, which does not always facilitate collaboration. This tension could be reduced through support staff being actively involved in the planning of learning and teaching strategies to ensure that the outcomes of national projects are linked to local initiatives (McNaught, 2002). The proposed Academy for the Advancement of Learning and Teaching in Higher Education could help strengthen these links.

\section{How can costs be reduced?}

The DfES consultation document suggests that e-learning can reduce costs in a variety of ways. First, e-learning can improve the running of the organization by automating administrative functions (DfES, 2003a, para 71). Second, it has the potential to increase teaching efficiency and may help address shortages of resources and teachers in certain subject areas (para 61). Thirdly, resources can be reused and shared across courses and subject disciplines (para 56). Over the past few years, cost-reduction strategies have largely focused on the reuse of content. However, other types of resources, such as student activities and course designs, can also be reused (Koper, 2003). All these types of resources can be copied and reused using Learning Management Systems (LMS), sometimes referred to as Virtual Learning Environments. An LMS is a software environment integrating a series of tools which can support a range of teaching and learning activities (Britain and Liber, 2000). Using these tools academic staff can set up online courses without the need for intensive IT training. Forum contributor, Barbara Newland, reported on her work in reusing course designs within a Learning Management System, Blackboard (SSeLF, briefing paper by Newland, 2003). For several years Newland has been developing strategies for supporting large numbers of academics in using Blackboard at the University of Durham. This support involves assisting academics in designing courses made up of reusable student activities as well as reusable content resources.

At Durham reusable content sourced from academics, audio-visual staff and publishing houses has been redeployed across several different modules. A range of student activities has also been reused. This includes online discussion tasks, group project assignments, computer-marked and computer-managed assessments as well as interactive simulations. In addition, academics have redeployed course designs that have proved to be effective (for examples, see the LEAP Website). These designs were duplicated within Blackboard and repurposed by the original course designer, or other academics. According to Newland, At the end of the academic year the course is ready for the next year with the same content and with a new set of students. The academic can just click radio buttons to make materials available or unavailable at certain dates.' 
Repurposing, rather than reusing resources, can feel more comfortable to academics and can help increase their teaching efficiency. Most academics already have content resources that they use during lectures and tutorial sessions and content from a single module can be digitized, redesigned and repurposed for reuse in other modules. Mary Thorpe described a process of repurposing content that has been pioneered at the UK Open University (Thorpe, Kubiak and Thorpe, 2003). During this process, existing learning resources, such as text documents, images, etc., are transformed into free-standing Learning Objects that can be updated, 'without creating knock-on effects to any other part of a course'. There are two critical factors that are essential to this process: clear structuring of texts that can easily be adapted during the authoring process, and the application of metadata, enabling the resources to be searchable (SSeLF, briefing paper by Thorpe, 2003).

The difference between repurposing and reusing content is important within the context of higher education, since most HE lecturers prefer to reuse their own materials. However, within the primary, secondary and further education sectors, there is a longstanding, pervasive culture of reusing standardized learning materials. Gerry Graham, of 'Learning and Teaching Scotland', presented his experiences in supporting teachers across Scotland to share digital learning resources. These resources are stored within a central digital repository. Teachers can search for Learning Objects by keying terms into a search tool. The search results return metadata information about each resource, such as the author, format and description of the resource. This information can help teachers quickly evaluate the suitability of each resource within their own teaching situation (SSeLF, briefing paper by Graham, 2003).

Learning Objects can be submitted to a repository in a variety of formats. During the process of uploading, the resources will be described using metadata elements holding information about the author, educational intent, etc. This information is linked to the Learning Object as metadata. To complete the upload process to the digital repository, the Learning Object is classified using an educational taxonomy. Metadata is crucial to this process for a variety of reasons. It enables searching and sourcing of content resources; it allows authorships and associated rights to be retained; it facilitates communication of educational intent; and it permits matching of learners' needs with appropriate content (SSeLF, Stiles briefing paper, 2003). Until now, most institutions have implemented Learning Management Systems that do not support these functions, restricting the reuse and sharing of resources and limiting opportunities to reduce costs.

\section{Forum responses}

Many forum delegates had attempted to reduce costs within their institution by encouraging the sharing and reuse of resources. However, this process was frequently complicated by a series of technological and social issues. Delegates identified several technological problems that had inhibited resource sharing with academic staff. In their experience, several commercial systems (such as Blackboard and WebCT) did not allow for easy resource sharing, resulting in duplication of materials within institutions. This shortcoming frequently led to further problems, since multiple copies of single resources had to be updated individually. Temporary solutions had been tested, including storing resources at a location outwith the Learning Management System and creating links to these resources from online courses contained within the LMS. However, this method had 
limited success, since there was no means by which academics could source available resources. The best solution was to store resources within a searchable database or digital repository.

Delegates confirmed they had encountered a variety of social factors inhibiting resource sharing. These included academics' confidence in sharing self-generated materials, concerns over Intellectual Property Rights (IPR), the time required by them to implement metadata tagging or to upload resources. Three potential solutions were suggested to improve confidence in sharing and reusing materials. First, to build academics' confidence in reusing resources by making available 'off the shelf' materials. Second, to encourage lecturers to reuse their own materials, initially by themselves, then with close colleagues within their subject discipline, school or faculty. Third, to advise academics to share students activities and course designs as well as content resources. While the use of metadata may reduce concerns in terms of IPR, the time required to describe resources with metadata is a major disincentive for most staff. A potential solution to this problem is to encourage lecturers to describe resources with small amounts of metadata. This would allow them to gauge the benefits of using metadata, without requiring a large, initial time input.

A major factor critical to the successful reuse of Learning Objects is the degree of ownership felt by the academic. Consequently resources are most likely to be reused by the original author. Resources created by a support unit have a greater chance of being reused if developed in partnership with the academic. However, externally generated resources have much less chance of being reused in higher education. Extensive funding has generated a variety of nationally available, reusable Learning Objects (for example X4L, RDN). In order to encourage the reuse of these resources closer links must be formed between these national initiatives and departments within institutions. Once again, the proposed Academy for the Advancement of Learning and Teaching in Higher Education could strengthen these links.

Delegates reported that few institutions had reduced costs through the automation of administrative functions. All the universities and colleges represented had implemented computer-marked assessment software, though student records usually had to be transferred to record systems manually. Some had linked computer-assessment software with student record systems. Although there were no reports of fully integrated systems, some institutions were planning to implement these within the next academic year. These integrated structures will have a major impact on the development of student portfolios (an area that will be further explored in phase 2 of the SSeLF forum).

A large proportion of the "reuse" debate has focused on content development. However, the strengths of higher education institutions lies in 'softer' areas. Mark Stiles summed this up by stressing that, "educational institutions do not sell "content", but rather the provision of access to expertise and support, assessment and accreditation of learning.' Therefore, it is important to explore ways in which educational benefits can be maximized.

\section{How can benefits be increased?}

The benefits of implementing sustainable e-learning can be viewed at three levels within an 
institution: educational, organizational and external (Nicol and Coen, 2003). Developments within the educational and organizational spheres will inevitably impact upon the external perception of an institution. If the technology is working well and students are being provided with better education, this will have a major, positive impact. Any negative impact is likely to reduce the potential for income generation, so enhancement in the educational sphere will focus on learning and the learner. Developments are likely to be influenced by the emergence of new systems that allow lecturers easily to design courses based on different educational models. One such approach, based on Learning Design, a notational system currently being developed by IMS (www.ims.org), was presented by Colin Tattersall of the Open University of the Netherlands (SSeLF, Tattersall briefing paper, 2003). Learning Design involves course designs in which students are assigned activities (or tasks) and roles (for example group moderator, reporter, etc.). Students have access to content appropriate to each task. The sustainability of courses is determined by the reuse of all these types of resources: content, activities and learning designs (Koper, 2003). This approach requires a shift in the way elearning is implemented and supported. Learning Management Systems that are being developed around Learning Design (see, for example, Dalziel, 2002) encourage academics to design courses that are based on student activities linked to learning objectives. According to Tattersall, 'It recognises that learning can happen without learning objects, that learning is different from content consumption and that . . . learning happens when learners cooperate to solve problems in social and work situations.'

A critical factor affecting reuse is the size of a Learning Object. Newland reported that smaller resources could be more easily adapted to specific learning contexts. These ideas were further explored by Boyle (2002), who presented his research examining the relationship between the degree of reusability of a Learning Object and its size. Boyle's aim was to ascertain whether or not a there is a favourable size that makes materials more reusable. He discovered that the size ultimately depends upon the 'level' of reuse. Boyle classified reuse at four levels. At a basic level simple 'information objects' or 'learning objects' could be reused. At a more complex level, these objects could be aggregated to form larger 'topic based learning activity structures' or 'course based learning activity structures'.

Boyle's research has demonstrated that the reuse of Learning Objects at different levels can improve learning. However, many lecturers remain sceptical of the value of using Learning Objects, believing this approach leads to a fragmented, reductionist pedagogy. This issue was explored by Robin Mason, of the UK Open University. Mason believes that designing courses comprising Learning Objects (both student activity and information resources) can 'provide a rich learning environment and allow for easy updating and re-versioning' (SSeLF, Mason briefing paper). The four areas in which she believes the reuse of Learning Objects can promote a student-centred approach to learning include the accommodation of learner diversity; learner choice and selection; activity or problem-based learning (which resonates with the Learning Design approach); and interactivity and collaborative work. She considers that, in the future, there is likely to be greater emphasis on developing the interactive and communicative nature of the Web. Students will create their own Learning Objects, upload these resources to a repository and draw upon those of their peers. Work is already under way to explore not only how to capture ideas, as Learning Objects, but the 
process by which these ideas were developed (DIDET). This may be achieved by capturing unwritten thoughts and courses of action as metadata.

When teachers create resources, they naturally embed them within a particular context. However, to extend their potential for reuse, resources should be context-free and should not contain information specific to a particular subject discipline or course. This contradicts the way that lecturers normally modify and adapt resources to fit specific teaching situations, disciplines and abilities of students. Patrick McAndrew addressed this critical issue by posing the following question: 'If some software, for example, is used in one situation to support learners working at a distance in their own time, and then the same software is used on campus in a fixed time tutorial, what is the most useful aspect to transfer across?' (SSeLF, McAndrew briefing paper). McAndrew drew upon five potential ways in which these aspects could be addressed: metadata tagging, open source courseware, Reusable Learning Objects, Reusable Learning Activities and community building. $\mathrm{He}$ concluded that automatic metadata tagging is a potential time-reducing incentive to encourage the uploading of resources to shared repositories. However, McAndrew voiced his concern that focusing development in this area may 'design the people out of systems when the subtlety of education means that they should be very much designed in'. His suggestion is to link multiple methods in order to provide a more holistic approach.

E-learning systems can enhance the organizational aspects of an institution by automating routine administrative processes. Unfortunately, most Learning Management Systems are not currently set up to allow lecturers to carry out these operations. Integration of a series of complex functions across an institution requires a strategic approach linking a range of policies, procedures, roles and responsibilities. According to Mark Stiles, it includes such things as staff development as well as quality assurance, procedures for the validation and approval of new courses, academic monitoring, and the various procedures associated with the recruitment, enrolment, charging, assessment and accreditation of students' (SSeLF, Stiles briefing paper, 2003). Stiles presented a case study of how this had been attempted at the University of Staffordshire, highlighting the ways in which interoperability standards had helped and hindered the process. While metadata was vital to operating a policy of reusing Learning Objects, the standards also proved to be restrictive. For example, when relocating a course to a new system, IMS Content Packaging allows the content to be packaged with a simple linear structure and transported. However, it does not preserve the more complex structure nor the educational intent (Wilson and Currier, 2002). Therefore it is essential that teachers and learners are involved in the standards debate to help develop standards that will underpin future systems that meet academics' and students' requirements (SSeLF, Corley briefing paper, 2003).

\section{Forum responses}

Several delegates were concerned that the current focus on reusing content has distracted lecturers from course design. As a result academic staff often begin designing courses by developing content, afterwards tagging learning design around the available content resources. Consequently, course designs tend to overemphasize the use of information resources, rather than leamer engagement in activities. In general, the smaller or more granular a resource the greater the possibility that it will be reused in another educational context. However, larger resources may have greater educational value and may be less time- 
consuming for a lecturer to reuse a larger resource, such as a learning activity, rather than constructing a course from its most basic components. Therefore, in terms of resource size, delegates identified a conflict between the educational value and the ease of interoperability.

Academics often have a clear idea about the content they want to use, but are most likely to require guidance and support in reusing course designs or activities. It is important that teaching staff are encouraged to design courses and develop student activities before deciding on the content resources. However, a significant number of support staff have limited understanding of pedagogical issues and might also tend to focus on content development. Therefore, in order to shift the focus from content to course design issues, it is critical that support units work cooperatively. This is most likely to happen when support staff are assigned clear roles and feel secure while working within multi-disciplinary teams.

Delegates reported that academics often confuse technological and educational issues. This arises from the fact that current Learning Management Systems do not allow easy development of courses based upon diverse educational models. Most systems adopt specific pedagogical approaches that tend to be fixed. This only allows any one LMS to be used within a limited range of contexts: use outwith this context usually requires a great deal of imagination and skill by the academic. Learning Management Systems are equally uncompromising in allowing students actively to negotiate assessments, to set up online discussions, or to develop and upload their own learning resources. Therefore, it is important that future Learning Management Systems should allow more flexible development of courses based on a wide variety of educational models. A prototype Learning Activity Management System (LAMS) is currently under development (Dalziel, 2002). While LAMs is not yet based on IMS Learning Design, it does use many of its elements.

A surprisingly large proportion of delegates were unaware of developments in Learning Design. This reflects the gap that exists between educational 'research' and 'practice' cultures. Many (though not all) of the support staff who are involved in current debates over the development of e-learning standards are involved in research. However, delegates perceived a mismatch between the ideas of the 'standards development community' and the practice of staff dealing with day-to-day learning and teaching issues. It is essential that the ideas being formulated by this research are fully tested in real situations if possible (with large numbers of students and within realistic timescales) and that the 'research' and 'practice' communities communicate more effectively.

\section{Commentary}

This forum has highlighted major challenges that concern the development of a unified elearning strategy. Many of these challenges are social and organizational issues, rather than pedagogical or technological concerns. Some are related to the fast rate of change elearning has experienced in recent years. This rapid change has led to anxiety for support staff, as well as tensions developing between support units, as mutual areas of engagement begin to overlap. If institutions are to take more responsibility for e-learning planning and provision (DfES, 2003a, para 59), the cooperative functioning of these units is an area deserving significant consideration.

Second, a related tension is the synergy between learning technology support staff and academic staff and the issue of deficiencies in communication between these groups. This 
issue is partly being resolved by the move away from a 'support' to a 'partnership' culture. These partnerships have, in some cases, extended to include work with students developing their own learning resources. These kinds of collaborations are likely to become increasingly important.

Third, there is a growing gap between institutional practice and research. This is likely to result in the benefits arising from research not being implemented at a local level. This problem is part of a wider issue in which national initiatives are not embedded within local institutions. National bodies, such as the Learning and Teaching Support Network, or the Academy for the Advancement of Learning and Teaching in Higher Education, could help forge stronger links.

Fourth, the continued use of imprecise terms without clear definition adds unnecessary intricacy to an already complex situation. The inconsistencies in terminology amongst elearning support staff will confuse the academics they support.

Finally, viewing e-learning as being somehow separate from other kinds of learning is not helpful when trying to devise new pedagogical designs (DfES, 2003a, para 56). It would be better to view e-learning as mainstream to learning and teaching practice, rather than as an add-on. This may help to disentangle the complexity of issues associated with different modes of teaching (distance learning, campus-based learning, continuing professional development, etc.).

In summary, the development of a unified strategy to promote sustainable approaches to elearning requires major shifts in support and leadership. Some of the greater challenges pertain to cultural and social issues, rather than technological concerns. These will be further explored in the next set of SSeLF forum sessions which are due to take place early in 2004.

\section{Acknowledgements}

The ideas within this paper have been amalgamated from a considerable body of work by the key contributors: Gerry Graham (LT Scotland), Lisa Corley (CETIS), Dr Colin Tattersall (OUNL), Professor Tom Boyle (London Metropolitan University), Professor Mark Stiles (University of Staffordshire), Dr Barbara Newland (University of Durham), Professor Robin Mason, Professor Mary Thorpe, Dr Patrick McAndrew (all from the Open University, UK), Dr Martin Oliver (University College London), Professor Gráinne Conole (University of Southampton) and Ros O'Leary (University of Bristol). I am indebted to them for their contributions and active involvement within the forum. Thanks also to my colleagues at the LTSN Generic Centre for their support: Kathy Wiles, Gill Harrison and Annita Hirons. Not least, I would like to thank the forum members, all of whom freely shared their thoughts and ideas.

\section{References}

Beetham, H. (2001), 'Career development of learning technology staff', JISC Scoping Study, http://www:sh.plym.ac.ukledsleffects/

Boyle, T: (2002), 'Design principles for authoring dynamic, reusable learning objects', Proceedings of ASCILITE 2002. http://www.unitec.ac.n=/ascilitelproceedings/papers/028.pdf 
Britain, S. and Liber, O. (2000), 'A summary of "A framework for pedagogical evaluation of virtual learning environments"', JTAP report, http://www.jisc.ac.uk/jtap/htm/ jtap-041.html

Campbell, L. M. (2003), 'Developing a learning object economy', chapter 4 in A. Littlejohn (ed.), Reusing Online Resources: A Sustainable Approach to e-learning, London: Kogan Page, 46-59.

Collis, B. and Moonen, J. (2001), Flexible Learning in a Digital World: Experiences and Expectations, London: Kogan Page.

Crook, C. (2002), 'The campus experience of networked learning', in C. Steeples and C. Jones (eds), Networked Learning: Perspectives and Issues, London: Springer-Verlag.

Crook, C. K. and Barrowcliff, D. (2001), 'Ubiquitous computing on campus: patterns of engagement by university students', International Journal of Human Computer Interaction, $13(2), 245-58$.

Dalziel, J., (2002), Implementing Learning Design: the Learning Activity Management System (LAMS), Proceedings of ASCILITE 2002, http://ww'w. adelaide.edu.au/ascilite2003/ docs/wsl3.pdf

Department for Education and Skills (DfES) (2003a), Towards a Unified e-Learning Strategy, Consultation Document, July 2003, http://www.dfes.gov.uk/consultations2/16/

Department for Education and Skills (DfES) (2003b), The Future of Higher Education, White Paper, January 2003, http://www:dfes.gov.uk/highereducation/hestrategy/foreword.shtml

Department for Education and Skills (DfES) (2003c), Widening Participation in Higher Education, Consultation Document, April 2003, http://www.dfes.gov.uk/highereducation/ docs/wideningparticipation.pdf

Draper, S. W., Brown, M. I., Henderson, F. P. and McAteer, E. (1996), 'Integrative evaluation: an emerging role for classroom studies of CAL', Computers and Education, 26, $17-32$.

Ehrmann, S. (1998), 'Studying, teaching, learning and technology: a toolkit from the Flashlight Programme', Active Learning, 9, http://www.ilt.ac.uk/public/ctilActiveLearning/ al9.html

Green, K. C. (1999), 'The continuing challenge of instructional integration and user support', The Campus Computing Project, http://www.campuscomputing.net/summaries/1999/

Harris, R. and Higgison, C. (2003), 'The reuse of resources across communities of practice', chapter 19 in A. Littlejohn (ed.), Reusing Online Resources: A Sustainable Approach to eLearning, London: Kogan Page, 234-47.

Ingraham, B., Watson, B., McDowell, L., Brockett, A. and Fitzpatrick, S. (2002), 'Evaluating and implementing learning environments: a United Kingdom experience', Educational Technology Review, 10, 2, http://www.aace.org/pubs/etr/issue3/ingraham.cfm

Jackson, R. H. (2002), 'Defining e-learning - different shades of 'online' . . a definitional protocol', http://www.hkwebsym.org.hk/2002/jackson_quote.html 
Kaplan-Leiserson, E. (2000), 'Learning circuits e-learning glossary', http://www.learning circuits.org/glossary.html\#E

Koper, R. (2001), 'Modelling units of study from a pedagogical perspective: the pedagogical meta-model behind EML', IMS Learning Design Working Group, http:/leml.ou.nllintroduction/docs/ped-metamodel.pdf

Koper, R. (2003), 'Combining reusable learning resources and services with pedagogically purposeful units of learning', chapter 5 in A. Littlejohn (ed.), Reusing Online Resources: A Sustainable Approach to e-learning, London: Kogan Page, 46-59.

Littlejohn, A. H. and Peacock, S. (2003), 'From pioneers to partners: the changing voices of staff developers', chapter 6 in J. Seale (ed.), From Individual Enthusiasm to Institutional Implementation: A Review of Learning Technology in Higher Education, Lisse, Netherlands: Swets \& Zeitlinger.

MacFarlane, A. (1998), Working Party of the Committee of Scottish University Principals (CSUP), Teaching and Learning in an Expanding Higher Education System, Lasswade: Polton House Press.

McNaught, C. (2002), 'Views on staff development for networked learning', in C. Steeples and C. Jones (eds), Networked Learning: Perspectives and Issues, London: Springer, 111-24.

National Committee of Inquiry into Higher Education (NCIHE) (1997), Higher Education in the Learning Society, http://www.leeds. ac.ukleducol/ncihel

Nicol, D. and Coen, M. (2003), 'A model for evaluating the institutional costs and benefits of ICT initiatives in teaching and learning in higher education', ALT-J, 11 (2), 46-60.

Oliver, M. (2002), 'What do learning technologists do?', Innovations in Education and Teaching International, 39 (4), 245-52.

Oliver, M. (2003), 'Rethinking the reuse of electronic resources: contexts, power and information literacy', Journal of Interactive Media in Education, 1, Special Issue on Reusing Online Resources, http://ww'w-jime.open.ac.uk/2003/1/

Oliver, R. and MacLaughlin, C. (2003), 'Pedagogical designs for sustainable and scalable online learning', chapter 8 in A. Littlejohn (ed.), Reusing Online Resources: A Sustainable Approach to e-learning, London: Kogan Page, 46-59.

Thorpe, M., Kubiak, C. and Thorpe, K. (2003), 'Design for reuse and versioning', chapter 6 in A. Littlejohn (ed.), Reusing Online Resources: A Sustainable Approach to e-learning, London: Kogan Page, 106-18.

Timms, D., Booth, S., Crompton, P., Klein, B, Bangali, L. and Schnuekel, B (1999), 'Review of telematics based open and distance learning', European Commission Educational Multimedia Taskforce Schema, http://www.schema.stir.ac.uk/Deliverables/D6.1.pdf

Wiles, K. and Littlejohn, A. (2003), 'Supporting sustainable e-learning: a UK national forum', Proceedings of the ASCILITE Conference, Adelaide, Australia.

Wilson, S. and Currier, S. (2002), 'What is IMS content packaging?', CETIS standards briefings series, CETIS 2002, http://www:cetis.ac.uk/lib/medialCPbrief.pdf 


\section{Websites}

DIDET, Digital Libraries for Distributed Innovative Design Education and Teamwork http://dmem1.ds.strath.ac.uk/didet/

LEAP, Learning, Environments and Pedagogy

http://www.ltsn. ac.uk/genericcentrelindex.asp?id $=17729$

RDN, Resource Discovery Network http://www.jisc.ac.uklindex.cfm?name=services_rdn

SSeLF, Supporting Sustainable e-learning Forum

http://wrw.ltsn.ac.uk/genericcentre/index.asp?id=18429

$\mathrm{X} 4 \mathrm{~L}$, Exchange for Learning Programme

http://www.jisc.ac.uklindex.cfm?name=programme_x4l 